\title{
Maternal exposure to low-level air pollution and pregnancy outcomes: a population-based study Ligita Maroziene* and Regina Grazuleviciene
}

\author{
Address: Department of Environmental Science, Vytautas Magnus University, Vileikos 8, Kaunas, Lithuania \\ E-mail: Ligita Maroziene* - l.maroziene@gmf.vdu.lt; Regina Grazuleviciene - r.grazuleviciene@gmf.vdu.lt \\ ${ }^{*}$ Corresponding author
}

Published: 9 December 2002

Environmental Health: A Global Access Science Source 2002, I:6

This article is available from: http://www.ehjournal.net/content/I/I/6

(c) 2002 Maroziene and Grazuleviciene; licensee BioMed Central Ltd. This is an Open Access article: verbatim copying and redistribution of this article are permitted in all media for any purpose, provided this notice is preserved along with the article's original URL.
Received: 8 October 2002

Accepted: 9 December 2002

\begin{abstract}
Background: Recent reports have shown that air pollution may increase the risk of adverse birth outcomes. We have evaluated the relationship between ambient air pollution and the occurrence of low birth weight and preterm delivery using routinely collected data in Lithuania.

Methods: This epidemiological study comprised all singleton newborns $(\mathrm{N}=3,988)$, born to women in 1998, who resided in the City of Kaunas. Birth data and information on maternal characteristics were obtained from the Lithuanian National Birth Register. To estimate residential exposure levels, we used measurements of ambient nitrogen dioxide $\left(\mathrm{NO}_{2}\right)$ and formaldehyde, which were collected at 12 monitoring posts. Multivariate logistic regression was used to estimate the effect that each pollutant would have on low birth weight (LBW) and premature birth while controlling for potential confounders.

Results: Adjusted odds ratios (OR) for LBW increased with increasing formaldehyde exposure

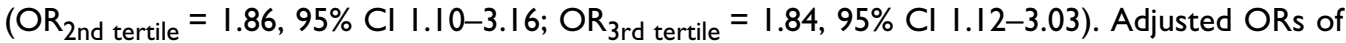
preterm birth for the medium and high $\mathrm{NO}_{2}$ tertile exposures were OR $=$ I. $14(95 \% \mathrm{Cl} 0.77-\mathrm{I} .68)$ and $\mathrm{OR}=\mathrm{I} .68(95 \% \mathrm{Cl} \mathrm{I} . \mathrm{I} 5-2.46)$, respectively. The risk of preterm birth increased by $25 \%$ (adjusted $\mathrm{OR}=1.25,95 \% \mathrm{Cl}$ I.07-1.46) per $10 \mu \mathrm{g} / \mathrm{m}^{3}$ increase in $\mathrm{NO}_{2}$ concentrations. An analysis by trimester showed that pregnancy outcomes were associated with first-trimester exposure to air pollutants. However, there were no significant relationships in other pregnancy periods between preterm birth and exposure to formaldehyde or between LBW and $\mathrm{NO}_{2}$ exposure.
\end{abstract}

Conclusion: Our findings suggest that in the City of Kaunas there might be a relationship between maternal exposure to ambient formaldehyde and the risk of LBW, as well as between $\mathrm{NO}_{2}$ exposure and the risk of preterm birth.

\section{Background}

Growing evidence of the adverse effect of air pollution on human health raises the question as to what extent this affects the foetus and the newborn, which are likely to be more vulnerable than adults to environmental toxicants [1]. Recent epidemiological studies, conducted in various countries, have reported relationships between elevated levels of air pollutants (total suspended particles (TSP), sulfur dioxide $\left(\mathrm{SO}_{2}\right)$, carbon monoxide $(\mathrm{CO})$, nitrogen dioxide $\left(\mathrm{NO}_{2}\right)$, polycyclic aromatic hydrocarbons (PAH)) and birth outcomes, such as low birth weight (LBW), prematurity, intrauterine retardation (IUGR) [2-16]. Howev- 
er, some studies produced non-positive findings [17-19]. Results differed between these studies in terms of number of pollutants examined, levels and time of exposure, confounding factors that were present, as well as types of pregnancy outcomes, and magnitude of observed effects. Replication of findings in different populations is a part of establishing a convincing relationship between air pollution and pregnancy outcomes [8].

The biological mechanisms by which air pollutants may interfere with the processes of prenatal development are still not clear. Several potential mechanisms have been hypothesised, including maternal susceptibility to infection, oxidative stress [20], haematological factors (e.g., blood viscosity) $[21,22]$ and the direct effect of specific pollutants on foetal development or on DNA and its transcription $[23,24]$.

$\mathrm{NO}_{2}$ is capable of oxidising tissue components (e.g., proteins, lipids) and of suppressing the antioxidant protective systems of organism [25]. Increased lipid peroxidation in the maternal and/or foetal compartment has been found in preterm birth [26]. In experimental studies it was found that exposure to $\mathrm{NO}_{2}$ during gestation induced increased lipid peroxidation in the placenta, elevated postimplantation embryonic lethality, and disturbances of postnatal development [27]. It was suggested that maternal exposure to $\mathrm{NO}_{2}$ can increase the risk of pregnancy complications through stimulation of the formation of celldamaging lipid peroxides and from decrease in maternal antioxidant reserves [20].

Although there is an opinion that adverse reproductive and developmental effects related to formaldehyde are minimal [28], recent occupational studies have shown some evidence of increased risk of spontaneous abortions [29] and reduced fertility [30] among workers exposed to formaldehyde. Experimental studies demonstrated that formaldehyde crosses the placenta and enters foetal tissues, and the hypothesis was suggested that formaldehyde might cause birth defects through oxidative stress and mitochondrial damage [31].

Formaldehyde, as well as $\mathrm{NO}_{2}$, may have direct toxic effect on the foetus, or serve as a proxy of other toxic chemicals from vehicle emission that could be related to the impaired foetal development.

Limited monitoring data and emission information is the main barrier to conducting population-based epidemiological studies on formaldehyde. The Kaunas municipal ecological monitoring system that measures major air pollutants $\left(\mathrm{SO}_{2}, \mathrm{NO}_{2}, \mathrm{TSP}\right)$ and formaldehyde, provided us with the opportunity to investigate the relationship be- tween maternal exposure to outdoor formaldehyde and $\mathrm{NO}_{2}$, and risk of having LBW or preterm newborns.

\section{Methods}

The study was conducted in Kaunas, the second largest city in Lithuania, which covers approximately $157.2 \mathrm{~km}^{2}$. The city, with about 400,000 inhabitants and 4,000 births per year, is situated in a valley and a neighbouring plain. Air pollution in Kaunas, as well as in the whole of Lithuania, has actually decreased during its transformational period of economic decline. During the last decade, the concentration of $\mathrm{SO}_{2}$ decreased to almost one-tenth, $\mathrm{NO}_{2}$ and TSP decreased to one-half, while no essential change was noted for formaldehyde levels [32]. The major air pollution source in the city is exhaust emissions from vehicles, which account for over $70 \%$ of the total emissions.

We conducted a population-based study within the municipality of Kaunas. Data on pregnancy outcomes were obtained from the Lithuanian National Birth Register. These registration records include information obtained through maternal interviews during the first prenatal visit and at delivery. The following information was available: home address at delivery, date of birth, gender, birth weight, gestational age estimated by the last menstrual period, parity, maternal age, education, marital status, employment status, past medical history including previous pregnancies, and maternal and paternal smoking status.

The study included all singleton births in the City of Kaunas from January $1^{\text {st }}, 1998$ through December 31st, 1998. The outcomes of interest were low birth weight (LBW, defined as birth weight of $<2500 \mathrm{~g}$ ), and premature birth (defined as birth at $<37$ weeks of gestation), according to Codes P07.0-3, International Classification of Diseases, $10^{\text {th }}$ revision.

To assess exposure to ambient air pollution, we used Kaunas' municipal ecological monitoring data. The measurements were taken from 12 municipal monitoring sites, one in each residential district. Monitors were located outside residential quarters, mostly near schools and kindergartens. Out of four routinely monitored air pollutants $\left(\mathrm{SO}_{2}, \mathrm{NO}_{2}\right.$, TSP and formaldehyde), we selected for analysis the two pollutants, which have essentially not decreased during the most recent decade. We used all available daily measurements of $\mathrm{NO}_{2}$ (colorimetric method) and formaldehyde (colorimetric method) to assess the mean residential exposure. By using recorded birth date as well as the gestational age at birth, we calculated the average air pollution level at the residence over the entire pregnancy period for each mother. In addition, we assessed the effects of average air pollution levels during the first, second and third trimester of gestation. We then examined the distribution of several known risk factors for 
LBW and preterm birth [33] across different exposure categories in order to identify potential confounders. Maternal age was divided into four age groups, i.e., $\leq 19,20-29$, $30-34, \geq 35$ years, with those aged $20-29$ years being considered the reference group. We classified marital status as married (reference), single, and divorced. We dichotomised education as lower than secondary $(<12$ years of education) and secondary or higher ( $>12$ years of education), with the latter being the reference group. Maternal and paternal smoking were categorised as 'yes' or 'no'. The other variables considered were gender of the child, parity, season of birth.

The effect of ambient air pollution on pregnancy outcomes was estimated by logistic regression. We calculated crude odds ratios (OR) and their 95\% confidence intervals (CIs) of LBW and pre-maturity across exposure categories for each pollutant. We adjusted crude effects of air pollution for potential confounding factors (in categories described above): gestational age (LBW model only), parity, maternal age, marital status, education, maternal and paternal smoking, season of birth.

We grouped the pollutant concentrations into three categories (tertiles) and applied the exposure variable as both categorical and continuous parameters. We used exposure levels in the $1^{\text {st }}$ tertile as the reference category (low exposure) for each pollutant and then also conducted an analysis of continuous exposure parameters on the basis of an increase of $5 \mu \mathrm{g} / \mathrm{m}^{3}$ in formaldehyde concentrations and an increase of $10 \mu \mathrm{g} / \mathrm{m}^{3}$ in $\mathrm{NO}_{2}$ concentrations.

We used SPSS version 10.0 for the statistical analyses.

\section{Results}

Out of 4,067 births registered in Kaunas in 1998, we excluded $70(1.7 \%)$ twins. Additionally, we excluded those whose birth registration records contained no valid information on gestational age $(\mathrm{N}=1)$, birth weight $(\mathrm{N}=2)$, maternal education $(\mathrm{N}=2)$ and marital status $(\mathrm{N}=6)$. These exclusions left 3,988 eligible subjects for study, and among them were 140 (3.5\%) LBW and 203 (5.1\%) premature births.

The mean formaldehyde concentration during the study period was $3.14 \mu \mathrm{g} / \mathrm{m}^{3}$ [standard deviation $(\mathrm{SD})=2.36$ $\left.\mu \mathrm{g} / \mathrm{m}^{3}\right]$. The mean $\mathrm{NO}_{2}$ concentration was $11.69 \mu \mathrm{g} / \mathrm{m}^{3}$ $\left(\mathrm{SD}=10.8 \mu \mathrm{g} / \mathrm{m}^{3}\right)$. Pearson's correlation coefficient $(\mathrm{r})$ for the averages of air pollutants during the whole pregnancy period showed that formaldehyde and $\mathrm{NO}_{2}$ were significantly associated $(\mathrm{r}=0.53, \mathrm{p}<0.01)$. This correlation may reflect the fact that both pollutants are produced by the same vehicular sources.
The distribution of births and potential risk factors for LBW and premature birth by different exposure categories is presented in Table 1 (see Additional file 1: Table1.doc). There were distinct differences with respect to maternal age, marital status, parity, paternal smoking and season of birth. LBW prevalence increased with increasing pollutant level from $2.9 \%$ in the low tertile formaldehyde exposure category to $4.0 \%$ in the high exposure category, and from $3.2 \%$ to $4.3 \%$ for the $\mathrm{NO}_{2}$ exposure categories. Similar patterns were also observed for premature births; the prevalence of pre-maturity increased from $4.9 \%$ to $5.6 \%$ for the formaldehyde exposure categories and from $4.5 \%$ to $6.2 \%$ for $\mathrm{NO}_{2}$ exposure categories.

The crude odds ratios for LBW also increased with each tertile of formaldehyde exposure (Table 12). After adjustments for known LBW risk factors (maternal age, marital status, education, season of birth, and parental smoking), the risk of LBW remained significantly increased for those newborns whose mothers were exposed during pregnancy to medium and high levels of formaldehyde, OR $=1.86$ (95\% CI 1.10-3.16) and OR = 1.84 (95\% CI 1.12-3.03), respectively. Further adjustment for gestational age slightly increased the ORs; however, this estimate remained statistically significant only in the high exposure category. For $\mathrm{NO}_{2}$ we observed an increased LBW risk in the high exposure category, although the estimate lacked statistical significance when fully adjusted, OR $=1.54(95 \% \mathrm{CI}$ $0.80-2.96)$.

While analysing the effects of exposure to pollutants on pre-maturity, we observed a dose-response pattern for $\mathrm{NO}_{2}$; adjusted ORs for medium and high exposures were $\mathrm{OR}=1.14(95 \% \mathrm{CI} 0.77-1.68)$ and $\mathrm{OR}=1.68(95 \% \mathrm{CI}$ 1.15-2.46), respectively (Table 23). Using a continuous measure, we estimated that the risk of preterm birth increased by $25 \%$ (adjusted OR $=1.25 ; 95 \%$ CI $1.07-1.46$ ) per $10 \mu \mathrm{g} / \mathrm{m}^{3}$ increase in $\mathrm{NO}_{2}$ concentrations. There was no significant association between preterm birth and exposure to formaldehyde.

An analysis of specific exposures by trimester revealed an increased risk of LBW associated with formaldehyde exposure in the first trimester (adjusted OR $=2.20 ; 95 \% \mathrm{CI}$ 1.00-4.85), while pre-maturity was related to first-trimester exposure to $\mathrm{NO}_{2}$ (adjusted OR $=1.67 ; 95 \%$ CI $1.28-$ 2.18) (Table 34). We found no such effect for any other trimester of gestation. When we entered both pollutants together to the model, the estimated effects did not change considerably, except that the effect of exposure to NO2 in the second trimester presented a risk of pre-maturity. 
Table 2: Crude and adjusted odds ratios (OR) for low birth weight by pollution exposure

\begin{tabular}{|c|c|c|c|}
\hline \multirow[t]{2}{*}{ Exposure } & Crude odds ratio & Adjusted* odds ratio & Adjusted $\dagger$ odds ratio \\
\hline & OR $(95 \% \mathrm{Cl})$ & OR $(95 \% \mathrm{Cl})$ & OR $(95 \% \mathrm{Cl})$ \\
\hline \multicolumn{4}{|c|}{ Formaldehyde Categorical variable (tertiles) } \\
\hline \multicolumn{4}{|l|}{ I (reference) } \\
\hline 2 & $1.27(0.82-1.95)$ & $1.86(1.10-3.16)$ & $2.15(0.96-4.81)$ \\
\hline 3 & $1.39(0.91-2.12)$ & $1.84(1.12-3.03)$ & $2.09(1.03-4.26)$ \\
\hline \multicolumn{4}{|c|}{ Continuous variable (per $5 \mu \mathrm{g} / \mathrm{m}^{3}$ increase in concentration) } \\
\hline & $1.07(0.74-1.53)$ & $1.10(0.75-1.64)$ & $1.36(0.75-2.47)$ \\
\hline \multicolumn{4}{|c|}{ Nitrogen dioxide Categorical variable (tertiles) } \\
\hline \multicolumn{4}{|l|}{ I (reference) } \\
\hline 2 & $0.95(0.6 \mathrm{I}-\mathrm{I} .47)$ & I.II (0.70-I.77) & $0.96(0.47-1.96)$ \\
\hline 3 & $1.37(0.91-2.07)$ & $1.64(1.04-2.58)$ & $1.54(0.80-2.96)$ \\
\hline \multicolumn{4}{|c|}{ Continuous variable (per $10 \mu \mathrm{g} / \mathrm{m}^{3}$ increase in concentration) } \\
\hline & $1.15(0.97-1.36)$ & $1.23(1.02-1.48)$ & $1.28(0.97-1.68)$ \\
\hline
\end{tabular}

* Adjusted for parity, maternal age $(\leq 19,20-29,30-34, \geq 35)$, marital status, education, season of birth, maternal and paternal smoking $\dagger$ As above plus gestational age

\section{Discussion}

Our findings suggest a relationship between ambient air concentrations of formaldehyde during pregnancy, and the likelihood of having LBW newborns, taking into account confounder adjustment for maternal age, marital status, education, season of birth and parental smoking. Further adjustment for gestational age attenuated the effect of $\mathrm{NO}_{2}$, but not for formaldehyde. A relationship was noted between the highest level of $\mathrm{NO}_{2}$ exposure and premature birth; whereas for formaldehyde we observed no such relationship. Trimester-specific analyses revealed elevated adjusted ORs for LBW in relation to formaldehyde exposure during the first trimester and likewise for prematurity in relation to $\mathrm{NO}_{2}$ exposure.

In our previous study we found a moderately increased LBW risk for formaldehyde exposures exceeding $3.50 \mu \mathrm{g} /$ $\mathrm{m}^{3}$ (adjusted OR $=1.37 ; 95 \%$ CI $=0.90-2.09$ ) [16]. The exposure levels in the earlier study were similar to the ones included in the present study (annual mean for formaldehyde was $3.14 \mu \mathrm{g} / \mathrm{m}^{3}$, range $1.36-5.28$ ). To our knowledge, no other epidemiological study has examined exposure to outdoor formaldehyde as a risk factor for adverse pregnancy outcomes.

Our results on increased risk for preterm delivery in relation to increasing levels of $\mathrm{NO}_{2}$ during pregnancy are consistent with the findings of a Czech study [9]. These authors reported a relation between maternal exposure to $\mathrm{NO}_{\mathrm{x}}$ in the first trimester and a slightly increased risk of premature birth (adjusted OR 1.10; 95\% CI = 1.00-1.21 per $50 \mu \mathrm{g} / \mathrm{m}^{3}$ increase in $\mathrm{NO}_{\mathrm{x}}$ ), but no association with LBW risk. However, a study on births in Southern California found no consistent effect of $\mathrm{NO}_{2}$ on preterm birth in regard to exposures during any of pregnancy trimesters 
Table 3: Crude and adjusted odds ratios (OR) and for premature birth by pollution exposure

\begin{tabular}{|c|c|c|}
\hline \multirow[t]{2}{*}{ Exposure } & Crude odds ratio & Adjusted* odds ratio \\
\hline & OR $(95 \% \mathrm{Cl})$ & OR $(95 \% \mathrm{Cl})$ \\
\hline \multicolumn{3}{|c|}{ Formaldehyde Categorical variable (tertiles) } \\
\hline \multicolumn{3}{|l|}{ I (reference) } \\
\hline 2 & $0.98(0.68-1.40)$ & I.II (0.72-I.7I) \\
\hline 3 & $1.16(0.82-1.63)$ & $1.37(0.91-2.05)$ \\
\hline \multicolumn{3}{|c|}{ Continuous variable (per $5 \mu \mathrm{g} / \mathrm{m}^{3}$ increase in concentration) } \\
\hline & $1.03(0.76-1.40)$ & $1.07(0.77-1.49)$ \\
\hline \multicolumn{3}{|c|}{ Nitrogen dioxide Categorical variable (tertiles) } \\
\hline \multicolumn{3}{|l|}{ I (reference) } \\
\hline 2 & I.0I (0.70-1.46) & $1.14(0.77-1.68)$ \\
\hline 3 & $1.40(0.99-1.98)$ & $1.68(1.15-2.46)$ \\
\hline \multicolumn{3}{|c|}{ Continuous variable (per $10 \mu \mathrm{g} / \mathrm{m}^{3}$ increase in concentration) } \\
\hline & $1.16(1.01-1.34)$ & $1.25(1.07-1.46)$ \\
\hline
\end{tabular}

* Adjusted for parity, maternal age ( $\leq 19,20-29,30-34, \geq 35)$, marital status, education, season of birth, maternal and paternal smoking

[5]. A Seoul study found an association between first-trimester $\mathrm{NO}_{2}$ exposure and LBW for term births [14].

Our study has several strengths. The study population was homogeneous with respect to ethnic culture, unified prenatal care, and health care system. Another strength of this study was the ability to adjust a number of potential confounding factors for LBW and premature birth, including gestational age, maternal age, marital status, education, season of birth, maternal and paternal smoking.

We did not have any information on some known LBW risk factors, such as maternal nutrition, pre-pregnancy weight, and occupational exposures. However, the risk factors for which we had no information were likely to vary independently of the average ambient pollutant levels and so should not confound the relationships we observed.
Misclassification of LBW cases as non-cases and vice versa was not likely, as birth weight data, recorded in the birth register, are generally considered reliable. The estimation of gestational age, based on the date of the mother's last menstrual period, was of course less reliable; therefore, some misclassification of preterm birth cases may have occurred. However, the assignment of cases was independent of exposure assessment. Therefore, such classification errors were probably non-differential and might therefore have tended to underestimate the air pollution effects.

The most important source of error and possible bias in our study - as was the case in most studies in which exposure was based on place of residence - was the possible misclassification of exposure. We estimated maternal exposure to pollutants based on average measures for the entire residential district. True personal exposure depends upon a number of exposure pathways; for example, time spent indoors versus time spent outdoors, time spent at 
Table 4: Trimester-specific odds ratios (OR)* of low birth weight and premature birth for pollution exposure

\begin{tabular}{|c|c|c|c|c|}
\hline \multirow[t]{3}{*}{ Pollutant } & \multicolumn{2}{|c|}{ Low birth weight } & \multicolumn{2}{|c|}{ Preterm birth } \\
\hline & Single pollutant model & Multiple pollutant model $\dagger$ & Single pollutant model & Multiple pollutant model $†$ \\
\hline & OR $(95 \% \mathrm{Cl})$ & OR $(95 \% \mathrm{Cl})$ & OR $95 \% \mathrm{Cl}$ & OR $95 \% \mathrm{Cl}$ \\
\hline \multicolumn{5}{|c|}{ Formaldehyde(per $5 \mu \mathrm{g} / \mathrm{m}^{3}$ increase in concentration) } \\
\hline |st trimester & $2.20(1.00-4.85)$ & $2.39(1.07-5.32)$ & $1.13(0.64-1.97)$ & $0.91(0.49-1.68)$ \\
\hline $2^{\text {nd }}$ trimester & $1.48(0.65-3.40)$ & $1.57(0.68-3.64)$ & $0.46(0.27-0.78)$ & $0.38(0.21-0.67)$ \\
\hline $3^{\text {rd }}$ trimester & $1.29(0.62-2.73)$ & $1.17(0.52-2.65)$ & $1.01(0.64-1.59)$ & $0.94(0.57-1.53)$ \\
\hline \multicolumn{5}{|c|}{$\mathrm{NO}_{2}\left(\right.$ per $10 \mu \mathrm{g} / \mathrm{m}^{3}$ increase in concentration) } \\
\hline |st trimester & $0.91(0.53-1.56)$ & $0.79(0.45-1.39)$ & $1.67(1.28-2.18)$ & $1.69(1.28-2.23)$ \\
\hline $2^{\text {nd }}$ trimester & $0.93(0.6 \mathrm{I}-\mathrm{I} .4 \mathrm{I})$ & $0.88(0.57-1.36)$ & $1.13(0.90-1.40)$ & $1.30(1.03-1.64)$ \\
\hline $3^{\text {rd }}$ trimester & $1.34(0.94-1.92)$ & $1.32(0.92-1.91)$ & $1.19(0.96-1.47)$ & $1.19(0.96-1.49)$ \\
\hline
\end{tabular}

* odds ratio adjusted for gestational age (low birth weight model only), parity, maternal age $(\leq 19,20-29,30-34, \geq 35)$, marital status, education, season of birth, maternal and paternal smoking $\dagger$ also adjusted for the other air pollutant assessed

specific locations such as at work or home, and migration into or out of a study area. Nevertheless, factors expected to contribute to differences between area-wide and individual exposures were most likely independent of exposure assessment, with a resulting underestimation of the effects of air pollution. Evidence has been provided that when area-wide measures of exposure to air pollution were used as proxies for personal exposures, then estimates of effects of pollutant effects were generally smaller than those based on exposure levels determined by personal sampling [34].

A wide range of agents, including passive smoking [35] and occupational exposures [36] have been found to increase the risk of adverse pregnancy outcomes, and insufficient control of other environmental risk factors could have influenced the observed associations. Because air pollution constitutes a complex exposure, the possibility exists that especially the formaldehyde measure may not only represent the toxic formaldehyde entity as such, but also several pollutants produced by the same sources.

\section{Conclusions}

Although the effects of unmeasured risk factors could not be excluded with certainty, our findings suggest that in the City of Kaunas there may be a relationship between maternal exposure to ambient formaldehyde and the risk of
LBW, as well as between $\mathrm{NO}_{2}$ exposure and the risk of preterm birth.

\section{List of abbreviations \\ $\mathrm{NO}_{2}$ Nitrogen dioxide}

OR Odds ratio

LBW Low birth weight

IUGR Intrauterine growth retardation

CO Carbon monoxide

$\mathrm{SO}_{2}$ Sulfur dioxide

TSP Total suspended particles

\section{Competing interests}

None declared.

\section{Authors' contributions}

RG conceived and designed the study, LM co-ordinated the study, performed statistical analysis and drafted the manuscript. Both authors read and approved the final manuscript. 


\section{Additional material}

\section{Additional File 1}

Additional file contains Table 1. Distribution of potential risk factors for low birth weight and premature births by exposure categories.

Click here for file

[http://www.biomedcentral.com/content/supplementary/1476069X-1-6-S1.doc]

\section{References}

I. Sram RJ: Impact of air pollution on reproductive health. Environ Health Perspect 1999, I07:A542

2. Williams L, Spence AM, Tideman SC: Implication of the observed effect of air pollution on low birth weight. Soc Biol 1977, 24: I-9

3. Alderman BW, Baron AE, Savitz DA: Maternal exposure to neighborhood carbon monoxide and risk of low infant birth weight. Public Health Rep 1987, 102:410-4I4

4. Ritz B, Yu F: The effect of ambient carbon monoxide on low birth weight among children born in southern California between 1989 and 1993. Environ Health Perspect 1999, 107:17-25

5. Ritz B, Yu F, Chapa G, Fruin S: Effect of air pollution on preterm birth among children born in southern California between I 989 and 1993. Epidemiology 2000, I I:502-5 I I

6. Wang $X$, Ding $H, X u$ X: Association between air pollution and low birth weight: a community-based study. Environ Health Perspect 1997, 105:514-520

7. Xu X, Ding $H$, Wang $X$ : Acute effects of total suspended particles and sulphur dioxides on preterm delivery: a communitybased cohort study. Arch Environ Health 1995, 50:407-4I5

8. Bobak M, Leon DA: Pregnancy outcomes and outdoor air pollution: an ecological study in districts of the Czech Republic 1986-8. Occup Environ Med 1999, 56:539-543

9. Bobak M: Outdoor air pollution, low birth weight and prematurity. Environ Health Perspect 2000, I08:173-I76

10. Dejmek J, Selevan SG, Benes I, Solansky I, Sram R: Fetal growth and maternal exposure to particulate matter during pregnancy. Environ Health Perspect 1999, 107:475-480

II. Dejmek J, Solansky I, Benes I, Lenicek J, Sram R: The impact of polycyclic aromatic hydrocarbons and fine particles on pregnancy outcome. Environ Health Perspect 2000, I 08: I I59- I I64

12. Rogers JF, Thompson SJ, Addy CL, Mckeown RE, Cowen DJ, Decoufle $\mathrm{P}$ : Association of very low birth weight with exposures to environmental sulphur dioxide and total suspended particulates. Am J Epidemiol 2000, I 5 I:602-6 I3

13. Maisonet M, Bush T, Correa A, Jaakkola J: Relation between ambient air pollution and low birth weight in the Northeastern United States. Environ Health Perspect 200I, I 09(suppl 3):35I-356

14. Ha E, Hong Y, Lee B, Woo B, Schwartz J, Christiani D: Is air pollution a risk factor for low birth weight in Seoul? Epidemiology 200I, I 2:643-648

I5. Hansteen I, Kjuus H, Fandrem SI: Birth weight and environmental pollution in the county of Telemark, Norway. Int J Occup Environ Health 1998, 4:63-70

16. Grazuleviciene R, Dulskiene V, Vencloviene J: Formaldehyde exposure and low birth weight incidence. J Occup Health 1998, 40:6 I67

17. Landgren $\mathrm{O}$ : Environmental pollution and delivery outcome in southern Sweden: a study with central registries. Acta Paediatr 1996, 85:136I-1364

18. Bhopal RS, Phillimore P, Moffatt S, Foy C: Is living near coking works harmful to health? A study of industrial air pollution. J Epidemiol Comm Health 1994, 48:237-247

19. Dolk H, Pattenden S, Vrijheid M, Thakrar B, Armstrong B: Perinatal and infant mortality and low birth weight among residents near cokeworks in Great Britain. Arch Environ Health 2000, 55:26-30

20. Tabacova S, Baird DD, Balabaeva L: Exposure to oxidized nitrogen: lipid peroxidation and neonatal health risk. Arch Environ Health 1998, 53:2|4-22|
21. Peters A, Doering A, Wichmann HE, Koening W: Increased plasma viscosity during an air pollution episode: a link to mortality? Lancet 1997, 349:1582-1587

22. Zondervan HA, Oosting J, Hardeman MR, Smorenberg Schoorl ME, Treffers PE: The influence of maternal whole blood viscosity on fetal growth. Eur J Obstet Gynecol Reprod Biol 1987, 25: 187-194

23. Sram RJ, Binkova B, Rossner P, Rubes J, Topinka J, Dejmek J: Adverse reproductive outcomes from exposure to environmental mutagens. Mutat Res 1999, 428:203-215

24. Perera FP, Jedrychowski W, Rauh V, Whyatt RM: Molecular epidemiologic research on the effects of environmental pollutants on the fetus. Environ Health Perspect 1999, I 07(suppl 3):45 I-460

25. Sagai M, Ichinose T: Experimental study on lipid peroxide formation and tumor-promoting effects of nitrogen dioxide and ozone. In: Oxidative Damage and Repair (Edited by: Davies KTA) Oxford, UK: Pergamon 1991, 5II-516

26. Moison RM, Palinckx JJ, Roest M, Houdkamp E, Berger HM: Induction of lipid peroxidation of pulmonary surfactant by plasma of preterm babies. Lancet 1993, 34 1:79-82

27. Tabacova S, Nikiforov B, Balabaeva L: Postnatal effects of maternal exposure to nitrogen dioxide. Neurobehav Toxicol Teratol 1985, 7:785-789

28. World Health Organisation: Air Quality Guidelines for Europe WHO Reg Publ Eur Ser 2000, 91 :87-91

29. Collins JJ, Ness R, Tyl RW, Krivanek N, Esmen NA, Hall TA: A review of adverse pregnancy outcomes and formaldehyde exposure in human and animal studies. Regul Toxicol Pharmacol 2001, 34:17-34

30. Taskinen HK, Kyyronen P, Sallmen M, Virtanen SV, Liukkonen TA, Huida O, Lindbohm ML, Anttila A: Reduced fertility among female wood workers exposed to formaldehyde. Am J Ind Med 1999, 36:206-212

3I. Trasher JD, Kilburn KH: Embryo toxicity and teratogenicity of formaldehyde. Arch Environ Health 200I, 56:300-3II

32. Juknys R, Zukauskaite I: Pagrindines Kauno miesto oro kokybes pokyciu tendencijos. In: Kauno miesto ekologinis monitoringas' 99. Aplinkos tyrimai ir vertinimas (Edited by: Juknys $R$, Kameneckas J, Kilikevièius G) Kaunas 2000, 7-I5

33. Lang JM, Lieberman E, Cohen A: A comparison of risk factors for preterm labor and term small-for-gestational age birth. Epidemiology 1996, 7:369-376

34. Navidi W, Lurmann F: Measurement error in air pollution exposure assessment. J Expo Anal Environ Epidemiol 1995, 5: I I I- I 24

35. Windham GC, Eaton A, Hopkins B: Evidence for an association between environmental tobacco smoke exposure and birthweight: a meta-analysis and new data. Paediatr Perinat Epidemiol 1999, 13:35-37

36. Savitz DA, Olshan AF, Gallagher K: Maternal occupation and pregnancy outcome. Epidemiology 1996, 7:269-274

\section{Pre-publication history}

The pre-publication history for this paper can be accessed here:

http://www.biomedcentral.com/content/backmatter/ 1476-069x-1-6-b1.pdf 